\title{
Antioxidant, Anti-Inflammatory and Wound Healing of Biosynthetic Gold Nanoparticles Using Mangosteen (G. Mangostona)
}

\author{
${ }^{1}$ Abdulkadir Mohammed Noori Jassim*, ${ }^{1}$ Gufran Mohammed Shafy, ${ }^{1}$ Mustafa Taha Mohammed, ${ }^{2}$ Safana \\ Ahmed Farhan, ${ }^{3}$ Omar Mohammed Noori \\ ${ }^{1}$ Department of Chemistry, College of Science, Mustansiriyah University - Iraq \\ ${ }^{2}$ Polymer Research Unit, College of Science, Mustansiriyah University - Iraq \\ ${ }^{3}$ Industries of Chemical and Physical Materials, Ministry of Science and Technology - Iraq
}

\section{Article information}

\section{Article history:}

Received: August, 19, 2021

Accepted: October, 11, 2021

Available online: October, 20, 2021

\section{Keywords:}

Antioxidant,

G. mangostana,

Gold nanoparticles,

Wound healing

\section{*Corresponding Author:}

Abdulkadir Mohammed Noori Jassim

kadirchem@yahoo.com

DOI:

https://doi.org/10.53523/ijoirVol8I2ID69

\begin{abstract}
In current research, the synthesis of gold nanoparticles was achieved via reducing of gold ions in aqueous solution with Garcinia mangostana (G. mangostana) peel extract. The optimum concentration of gold (Au) solution, concentration ratio of Au solution and extract, temperature, time and $\mathrm{pH}$, the synthesized AuNPs (G. mangostana-gold nanoparticles) were studied by using UV-Vis, FT-IR, AAS, AFM, SEM and Zitasizer. The absorbance peak is noticed between $535-550 \mathrm{~nm}$ via UV-Vis spectroscopic method. The SEM, AFM analysis were proofed the particle as spherical in structure and their size between 15-100nm. Therefore, mechanism of AuNPs synthesis had been suggested. Also, the antibacterial activity was examined using different bacteria as well as free radical scavenging activity was tested using 1,1-Diphenyl-2picrylhydrazyl (DPPH). The AuNPs produced through biosynthesized method indicated a much elevated antioxidant activity as compared to peel extract of G. mangostana. Toxicity of the NPs and extract were tested via giving orally dose $50 \mathrm{mg} / \mathrm{b} . \mathrm{w}$. to mice. Diagnosis of the data (pathological changes) indicated that the AuNPs was non-toxic. The G. mangostana peel extract and AuNPs synthesized by this extract were converted to a cream and used as a wound healing cream. As a results, the AuNPs exhibited important role in wound healing progression compared to control, which may be attributed to their anti-inflammatory, antibacterial and antioxidant activities. Therefore, this research confirms its important use of AuNPs and can be utilized as promising agents for in the development of new drugs.
\end{abstract}

\section{Introduction}

Nanotechnology can be defined as the using of nano-materials for human being benefits. Nano-materials have unique properties because of their physico-chemical feature at the nanoscale [1]. Nanoparticles (NPs) are exceedingly used in medical and pharmaceutical scopes. They are utilized in many chemicals, such as shampoo, 
soap, detergent, cosmetics and toothpaste [2]. Gold NPs are used as carriers for the transfer of drugs and genes because they are small in size, so they can approach the biological target [3]. In general, most toxicological studies of NPs (from 4 to $18 \mathrm{~nm}$ ) have excluded that these particles are non-toxic [4].

Biosynthesis or green synthesis is a development method, easily handle as well as dominance the size, shape of NPs. Plant-based method (biosynthesis) is comparatively safe, fast, light and acts under room environment (condition) without the need to a great physical requirements [5]. García mangostana (G. mangostana Lin) can be classified within the Guttiferae family has different medical benefit such as anti-inflammatory, antitumor, antioxidant, antifungal, antibacterial, cosmetic uses, so it is used in medicinal and pharmacological field. It is a tree with 7-8m high, known only from cultivation in South East Asia [6]. The peel of the fruit contains large amounts of phenolic and antioxidants components, such as terpenes, tannins, flavonoids and polyphenols [7]. Free radicals like hydroxyl and superoxide known as Reactive Oxygen Species (ROS). The aggregation of ROS can lead to oxidative stress [8]. The antioxidants decrease the level of free radicals in the tissue by their self-repairing mechanisms in the cell [9].

A wound can be defined as a disruption of cellular, anatomic continuity of a tissue with or without microbial infection [10]. Inflammation has a complex biological response from vascular region of tissue, to harmful stimuli, pathogens, irritating from redness, warmth, swelling and pain [11]. The process of wound healing be composed of different stages: hemostasis, sore, proliferation, cell migration, tissue reformation or dissolution [12]. There is not much research with regard to the toxicity of AuNPs to human cells and this need to be taken into consideration when applying these particles for medical uses [13]. Here, we study the toxicity of AuNPs on animal models and converted these particles to cream to be used as a wound healing agent.

\section{Experimental Procedure}

\subsection{Preparation of G. Mangostana Peel Extract}

G. mangostana fruits were collected from local market. The peels were left for 15 days to dry at room temperature, ground into fine powder, then (at room temperature) stored for later used. The peel of this extract was made via putting of $2.50 \mathrm{~g}$ of powder from this powder in distilled water $(100 \mathrm{ml})$, left at $60{ }^{\circ} \mathrm{C}$ for two Hours. The peel extract has been filtered using filter paper and kept in test tube at $4-5^{\circ} \mathrm{C}$ for further used [5].

\subsection{Biosynthesis of Gold Nanoparticles}

In a test tube $1 \mathrm{ml}$ of peel extract was mixed with $1 \mathrm{ml}$ from $1 \mathrm{mM}$ of tetrachloroaurate $\left(\mathrm{AuHCl}_{4}\right)$ at room temperature. Changing of reaction color as well as time for this change were recorded. The color was immediately converted from pale brownish to red, referring to AuNPs biosynthesis [5].

\subsection{Fixation of Different Parameters}

\section{(a) Temperature}

Temperature of reaction was maintained at $\left(15,20,40,60,80\right.$, and $\left.100{ }^{\circ} \mathrm{C}\right)$, respectively, by using a water bath (shaker). Other optimized circumstances were used.

\section{(b) Time}

Time required for biosynthesis was monitored (0 to $60 \mathrm{~min}$, with $10 \mathrm{~min}$ as time interval). Other optimized circumstances were used.

\section{(c) Concentration of $\mathrm{AuHCl}_{4}$ Solution}

The $\mathrm{AuHCl}_{4}$ concentration was maintained using the concentration $(10,5,2,1,0.5$, and $0.1 \mathrm{mM})$ respectively. Other optimized circumstances were used.

\section{(d) Ratio of $\mathrm{AuHCl}_{4}$ Solution and Extract}

The $\mathrm{AuHCl}_{4}$ solution and extract required for the production of AuNPs, was monitored by using different ratios of $\mathrm{AuHCl}_{4}$ and extract $(1: 1,2: 1,3: 1,4: 1,1: 2,1: 3$, and 1:4), respectively. Other optimized circumstances were used [14]. 


\subsection{Characterization of AuNPs}

\section{(a) UV-Vis Spectra}

The analysis of UV-Vis spectral has been done via spectrophotometer (T80, PG Instruments Limited, Germany). The reduction of AuNPs was formed at uniformed intervals of 300 to $1000 \mathrm{~nm}$.

\section{(b) FTIR}

After biosynthesis of AuNPs, centrifuged at $5000 \mathrm{rpm}$ were done for 15 minutes. The process was repeated three to five times. Then the precipitate was dried in the oven $\left(4\right.$ hours at $40{ }^{\circ} \mathrm{C}$ ). For comparison, the biosynthesis AuNPs and G. mangostana peel extract were characterized via FTIR spectrophotometer (shimadzu-8400S), the recorded spectrum was done with range 500 to $4000 \mathrm{~cm}^{-1}$.

\section{(c) AFM}

The Atomic Force Microscope (AFM) (Model AA3000, Angstrom Advance Inc., USA) was used to inspection of size as well as size distributions of the biosynthesis AuNPs.

\section{(d) Zeta Potential}

Zeta potential assay was used to characterize the components of nanomaterial. This technique measure light dispersion using the Zeta Plus tool (Brookhaven Instruments Corp., USA).

\section{(e) SEM}

Utilizing of scanning electron microscopy (SEM) (Angstrom Advanced Inc.-AIS2300C), to identify the shape and morphology of AuNPs.

\section{(f) Atomic Absorption}

The AuNPs concentration was measured by atomic absorption spectrometry (AA-680Shimadzu, Japan) [14].

\subsection{Qualitative Estimation of Free Radical Scavenging Activity (Using TLC Method)}

The antioxidant content was examined by TLC and then using DPPH (2, 2- Diphenyl-1-picrylhydrazyl) [15].

\subsection{Quantitative Estimation of Free Radical Scavenging Activity (Using DPPH Method)}

The scavenging activity of AuNPs was examined by DPPH method [15]. Standard (Gallic acid) was used. The quantity of sample necessary to decrease the initial concentration of DPPH by $50 \%\left(\mathrm{IC}_{50}\right)$ was calculated graphically and percentage of inhibition for scavenging DPPH radical was estimation by:

DPPH scavenging radical activity $\%=[1-($ A Test sample or Standard/A Control) $] \times 100$

A control $=$ Absorbance of DPPH alone

A sample $=$ Absorbance of DPPH along with different concentrations of G. mangostana peel extract or standards

\subsection{Antimicrobial Activity via Well Diffusion}

AuNPs biosynthesized from $G$. mangostana peel extract were examined via method of well diffusion to show their antimicrobial activity for different organisms: First: Staphylococcus aureus ( $S$. aureus); second one Escherichia coli (E. coli). The tested samples ( $\mathrm{S} 6=$ AuNPs $13.6 \mathrm{ppm} / \mathrm{mL}, \mathrm{S} 8=$ G. mangostana peel extract $2.5 \mathrm{~g} / 25 \mathrm{~mL}$ ), respectively were prepared using the stock solution (S1 equal to $53.65 \mathrm{ppm}$, characterized via AA spectroscopy) by serial dilution using deionized water [14].

\subsection{LD50 Examination}

In this research, clinical observation has been identified for $24 \mathrm{hr}$ up to fourteen days. Thirty male of adult albino mice were divided up to four groups; each group consist of five mice with weight range between (25-30g), all groups deals orally via gastric gavage which given at once/day with various doses of each extract, and mice were kept under continued monitoring (24 hours). The groups were divided as following; First one (1): as control group, which taken a distilled water, second one (2): taken a AuNPs at concentration of $8.6 \mathrm{ppm} / \mathrm{mL}$ orally dose one time, by gastric lavage, third one (3): taken a AuNPs at concentration of $4 \mathrm{ppm} / \mathrm{mL}$ orally dose one time, by gastric lavage, fourth one (4): taken a AuNPs at concentration of $2 \mathrm{ppm} / \mathrm{mL}$ orally dose one time, by gastric lavage. All of 
the mice (lab animal) were sacrificed at the end of $\mathrm{LD}_{50}$ examination, and vital organ (brain and liver) used for histological study [16].

\subsection{Histological Study}

After 24 hours of last dose treatment, all mice were sacrificed. Vital organ (brain and Liver) has been dissected. In vessel contain formalin 10\% were kept for histological study. Vital organ (brain and Liver) were dehydrated in concentrated alcohols, later, embedded deeply in paraffin, cut into segments between 4-5 $\mu \mathrm{m}$ of thickness, stained with hematoxylin and eosin (H\&E) for microscopical study. The slides has been tested under 40X magnification using an optical microscope [17].

\subsection{Wound Healing for Mice}

After the lab animals were anaesthetized, dorsal fur was shaved. Also a full thickness of the excision wound of 0.5 $\mathrm{cm}^{2}$ was created along the markings via a surgical blade and pointed scissors. Entire wound was left open until redness is indicative of acute inflammation. The wound closure rate was assessed by tracking the wound in each day until healed. The mice were treating on a daily basis and any remark that appear through this treatment was documented and any changes in behavior that lab animal exhibits were monitored [18].

\section{Results and Discussion}

\subsection{Biosynthesis of Gold Nanoparticles}

The G. mangostana peel extract work as reducing agent to gathering with stabilizing agent, while the salt $\mathrm{HAuCl}_{4}$ $(1 \mathrm{mM})$ works as Au precursor. The $\mathrm{HAuCl}_{4}$ reduction has been confirmed via color changes of $G$. mangostana as illustrated in Figure 1. The process began by changing the color of the peel extract from pale brownish to red color during 15 min to indicating the AuNPs biosynthesis.

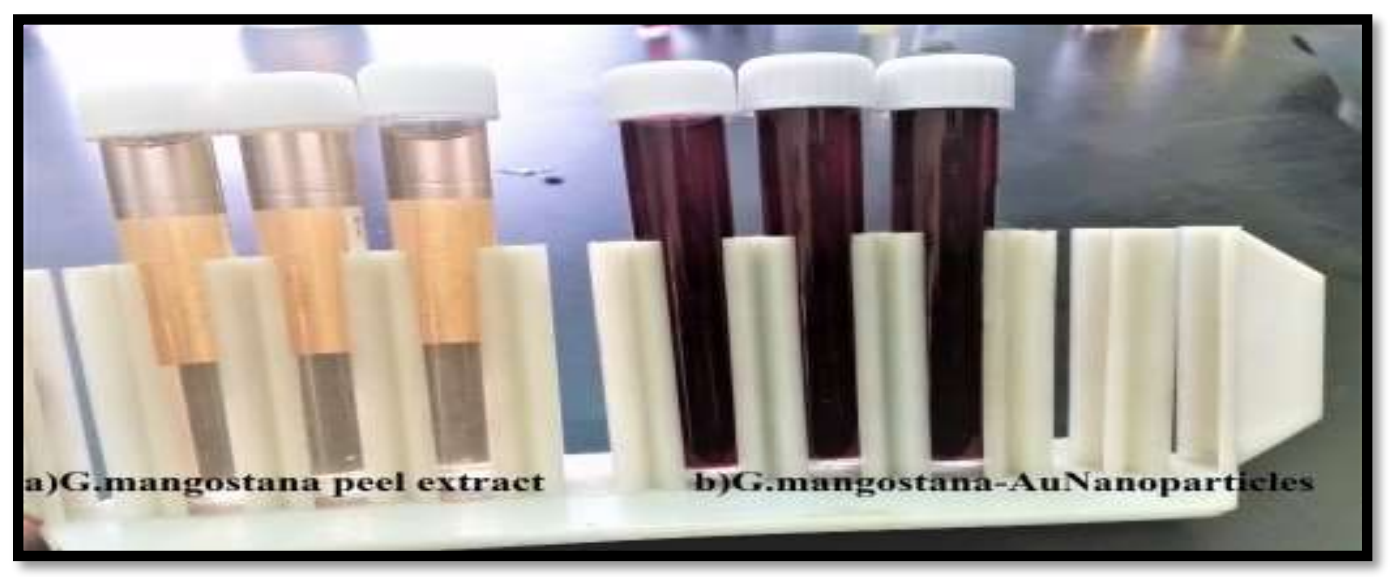

Figure (1). The color changes of G. mangostana peel extract (Left) from pale brownish into red indicating the AuNPs biosynthesis (Right).

\subsection{Fixation of Different Parameters}

\section{(a) Temperature}

As temperature elevated, the formation rate of AuNPs also accelerates. As well as the particle size is reduced because of reduction in growing particles during the aggregation. Elevating of temperature near $\left(20^{\circ} \mathrm{C}\right)$ activate the growth of the crystal around the nucleus as shown in Figure (2). 
NANO 2021

Special Issue

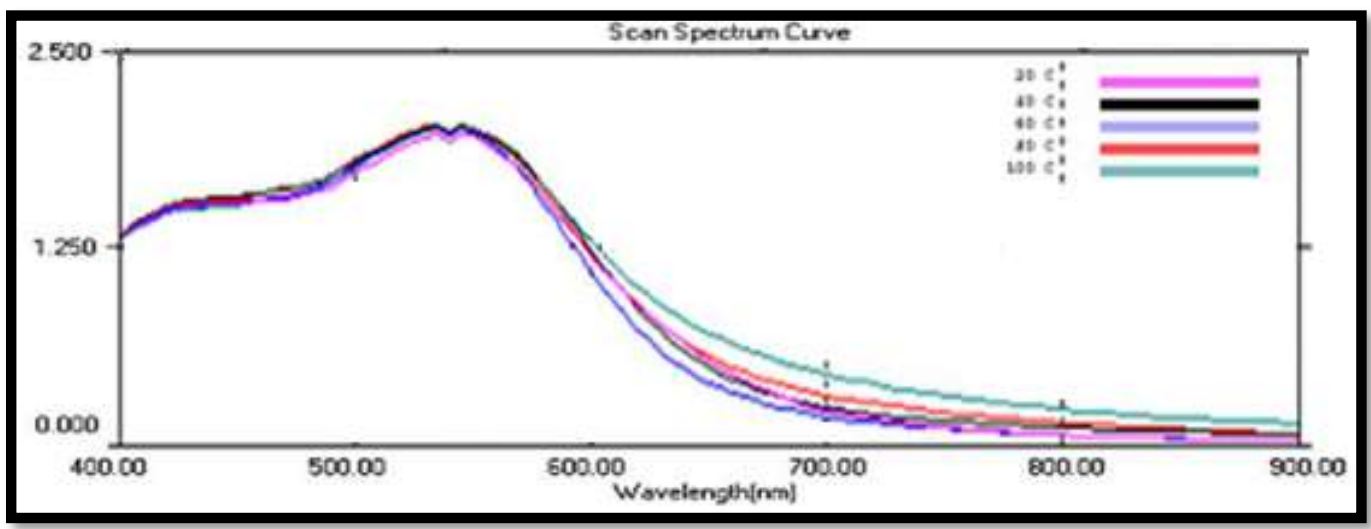

Figure (2). The UV-Vis spectra as a function of temperature.

\section{(b) Time}

Time required to ending of AuNPs biosynthesis was studied. Elevating of reaction time produced by elevating of the absorbance peak with SPR near $546 \mathrm{~nm}$ and intensity of color was elevating, also, with incubation time. However, peak intensity of SPR was elevated as the reaction time increased, which confirmed the increased in AuNPs concentrations. So, the optimum time required to ending of reaction in the current research was 15 min as indicated in Figure (3).

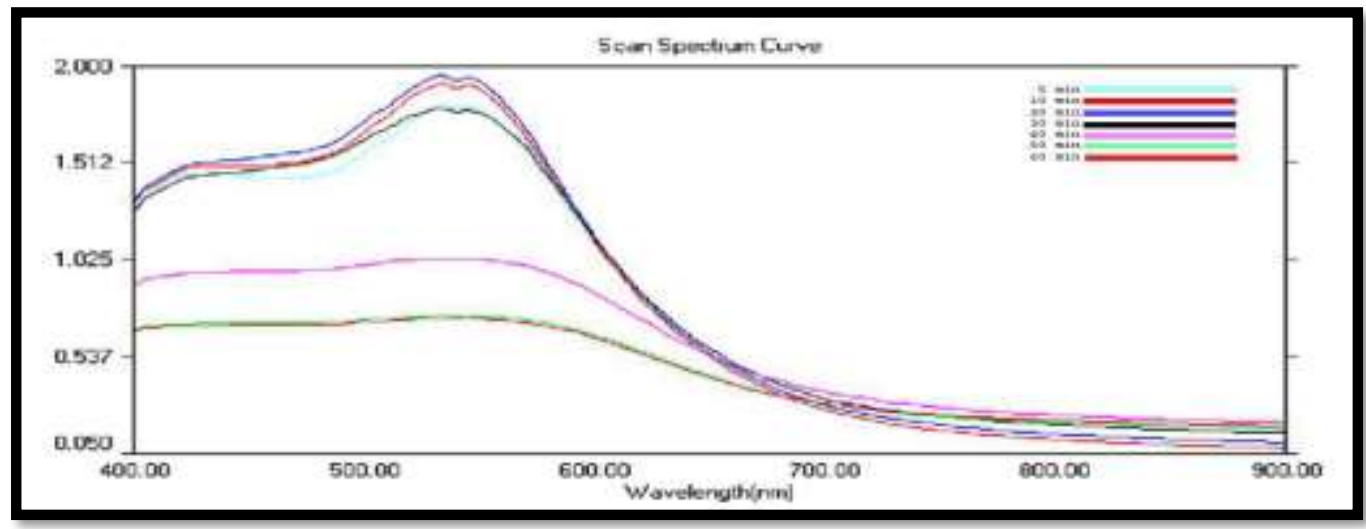

Figure (3). The UV-Vis spectrum as a function of time.

\section{(c) Concentration of Au Solution}

Different concentrations of Au solution were prepared to get maximum yield of AuNPs with $1 \mathrm{mM}$ gold solution as shown in Figure (4). As the concentration of Au increased, the intensity of the color also increased from red to deep brown and precipitation of gold particles on the walls of the tube. The SPR peak for AuNPs became distinct with elevating concentration of Au solution. The Plasmon bands has a broad with an absorption tail in the longer wavelengths as concentration of Au elevated, this illustrated an enhancement in particles size [19]. Also, the intensity of the color elevated as it depended upon the size of AuNPs. So, to get control growth and smaller particle size, it has been used $1 \mathrm{mM}$ of Au solution in the further steps. 
NANO 2021

Special Issue

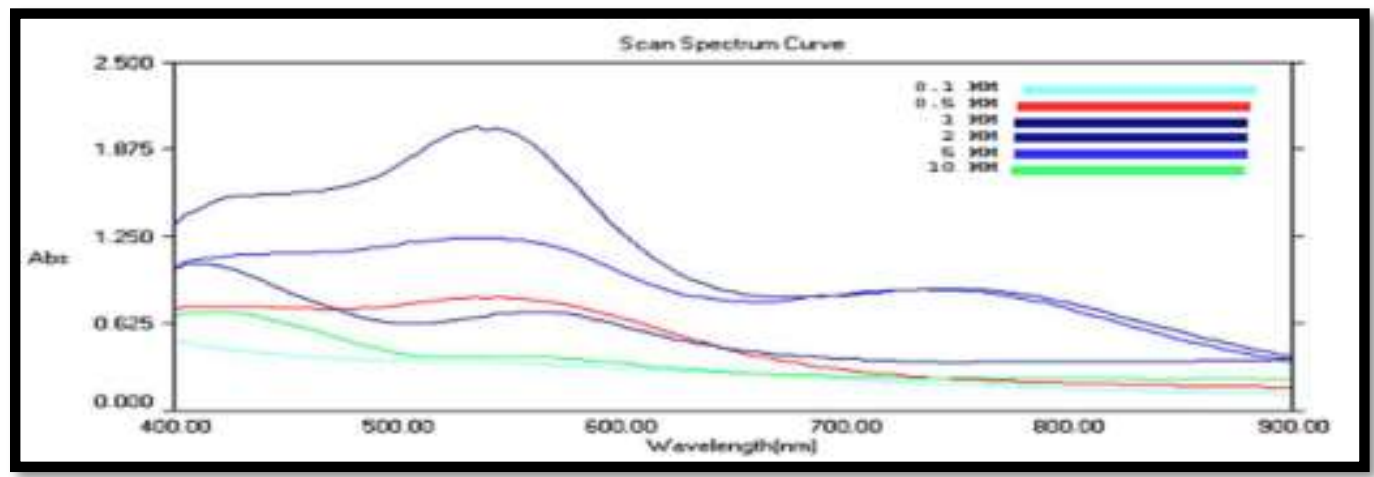

Figure (4). The UV-Vis spectum as a function of Au and G.mangostana.

\section{(d) Concentration Ratio of Gold and Peel Extract}

The optimization of gold and G.mangostana peel extract concentrations required for the maximum production of AuNPs, which monitored by using a different ratio of gold and the peel extract to investigate the optimum composition to maximize the yield of AuNPs (Figures $5 \& 6$ ). It was found that the optimum ratio for the reaction is $2: 1$ based on the number of trials and the optimum absorbance.

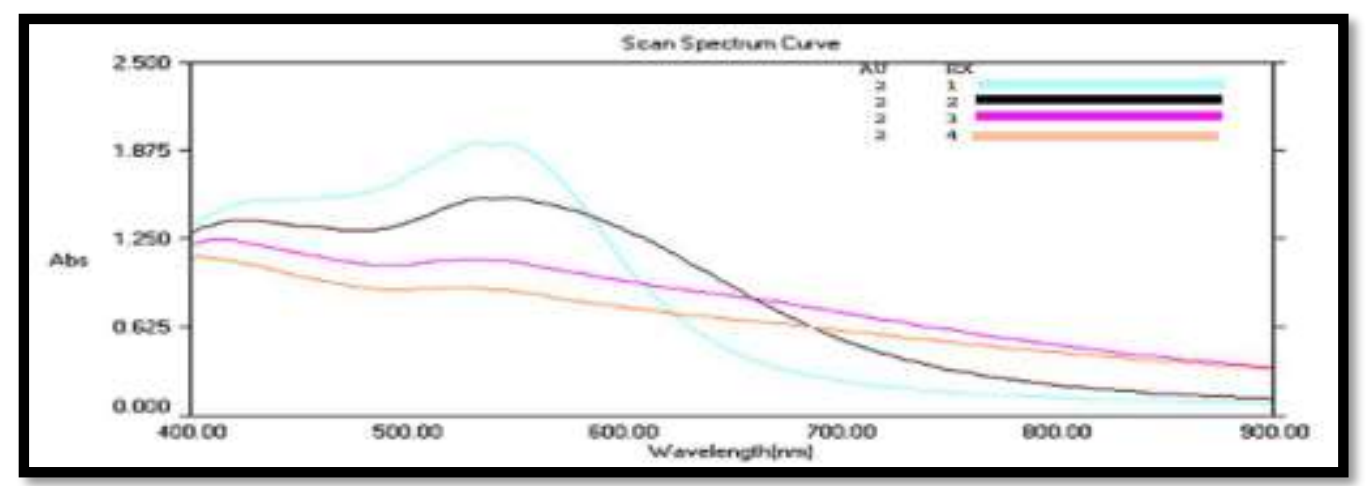

Figure (5). The UV-Vis spectrum as a function of ratio for $\mathrm{Au}$ (variable) and the peel extract (constant).

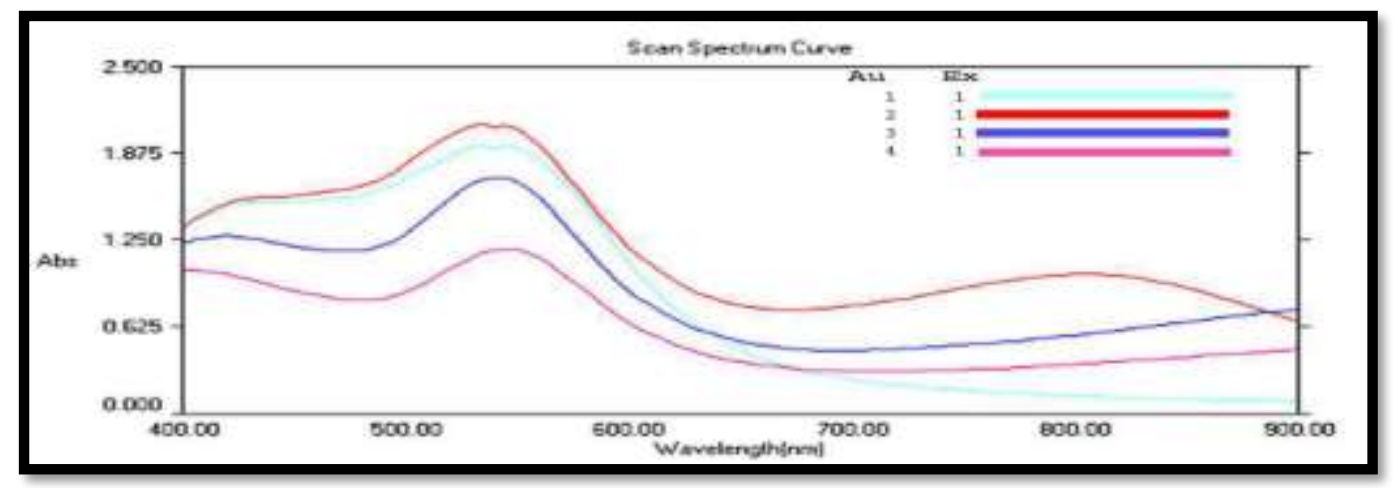

Figure (6). The UV-Vis spectrum as a function of ratio for Au (constant) and the peel extract (variable).

\subsection{Characterization of AuNPs:}

\section{(a) UV-VIS}

Existence of biosynthesis Au-NPs was established via UV-Vis spectrum as shown in Figure (7). The data indicated that there is no apparent peak for peel extract. Then, after $\mathrm{HAuCl}_{4}$ addition, a peak was noticeable at between 535$550 \mathrm{~nm}$. this peak confirmed the preparation of spherical shape (mono-dispersed) biosynthesis AuNPs [20]. Reaction occurs within 15 minutes with clear color change. 


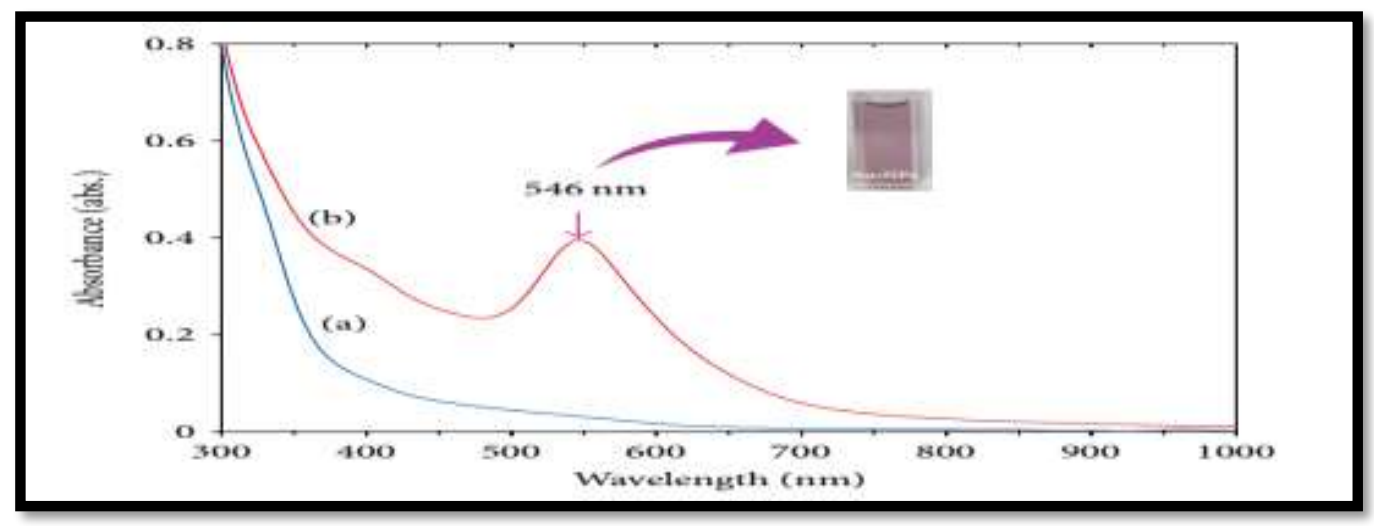

Figure (7). UV-Vis bands for -a- pure G. mangostana peel

\section{(b) FTIR}

extract and -b- AuNPs.

The FTIR measurement was has been done to confirm the likely bio-reducing molecules in G.mangostana peel extract (Figure 8, A) which bound specifically to AuNPs. The biosynthesis AuNPs (after its reaction with $\mathrm{HAuCl}_{4}$ ) has been shown in Figure (8b).

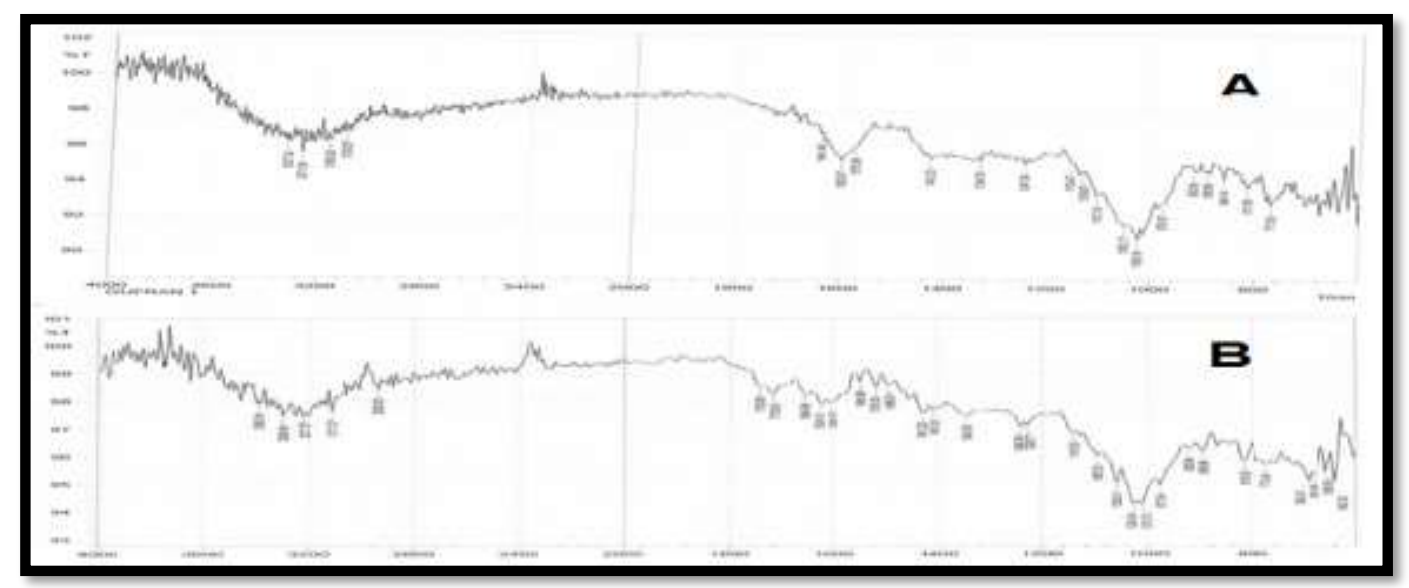

Figure (8). FTIR spectrums of G. mangostana peel extract (A) and synthesized AuNPs (B).

The major stretching appearing at $3000-3500 \mathrm{~cm}^{-1}$ indicates the presence of $\mathrm{O}-\mathrm{H}$ stretch which signifies the presence of phenols, flavonoids and benzophenones [21]. Some shifting was happen, indicating that the group of carbonyl in the peel extract capped and stabilized the AuNPs [22]. Also, O-H stretching, in $2933 \mathrm{~cm}^{-1}, 3103 \mathrm{~cm}^{-1}$ indicating to the presence of $\mathrm{C}-\mathrm{H}$ bond in xanthone [23] as well as to other component in this peel extract. Peaks of $\mathrm{C}-\mathrm{H}$ bond from this peel extract split into two bands, $3271 \mathrm{~cm}^{-1}, 3296 \mathrm{~cm}^{-1}$, refer to, after the biosynthesis of AuNPs, the transmittance exchanged [24]. Eventually, C-O-C stretch can be exist between range of $1300 \mathrm{~cm}^{-1}$, where shifting happen from $1247 \mathrm{~cm}^{-1}$ to $1226 \mathrm{~cm}^{-1}$ during the capping process with biosynthesized AuNPs [25]. The above peaks are matching with the components that found in the extract, indicating that they are may be contributed in reduction as well as stabilization of $\mathrm{HAuCl}_{4}$ to AuNPs.

\section{(c) AFM}

The biosynthesized AuNPs has been characterized via AFM analysis in term of size and morphology of AuNPs. The origin of the surface morphology of the irregularly shaped particles sizes and the size distribution broaden of biosynthesized using G. mangostana has been illustrated in Figure 9. The particle size (average) of biosynthesized AuNPs was equal to $63.82 \mathrm{~nm}$. 


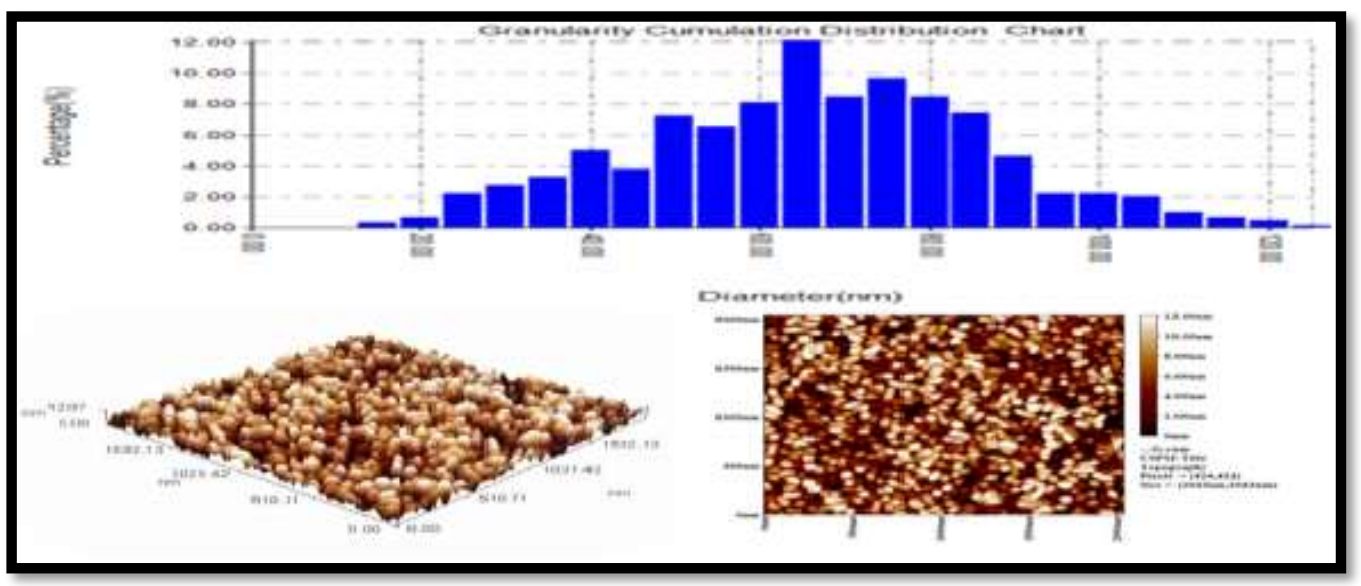

Figure (9). AFM images and size distributions of AuNPs

\section{(d) Zeta Potential}

Stability of biosynthesized AuNPs was achieved by zeta potential analysis. The value of zeta $\pm 30 \mathrm{mV}$ is needed for suspension to be known as physically stable, while a value $\pm 20 \mathrm{mV}$ is necessary for a combined electrostatic and steric condition [21]. As a results of zeta value, for pure G. mangostanapeel extract are $-19.74 \mathrm{mV}$ [26], while their reduced to $-20.85 \mathrm{mV}$ for biosynthesized AuNPs (Figure 10). Thus, biosynthesized AuNPs indicate an acceptable stability with reading not less than the required stable expression.

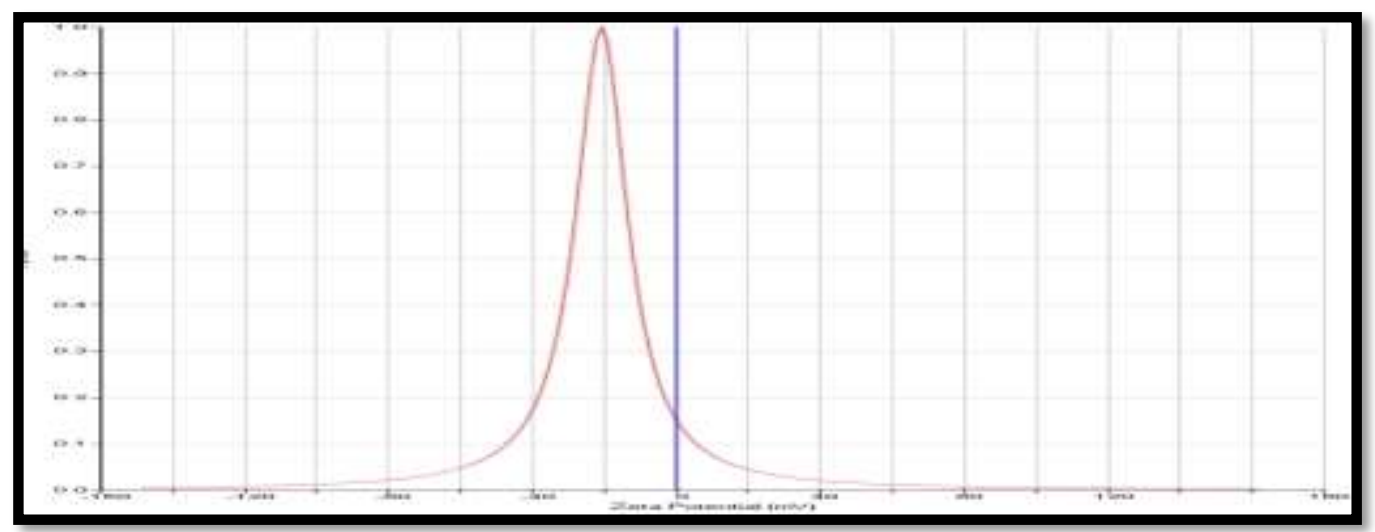

Figure (10). Zeta potential distribution of AuNPs

\section{(e) SEM}

The SEM analysis illustrated in Figure (11), was achieved to show the structure as well as morphology of the biosynthesized AuNPs to confirm further insight into the features of this particles obtained from biogenic synthesis method, the image illustrated relatively spherical in shape of the biosynthetic NPs with a diameter ranging between $15-125 \mathrm{~nm}$.
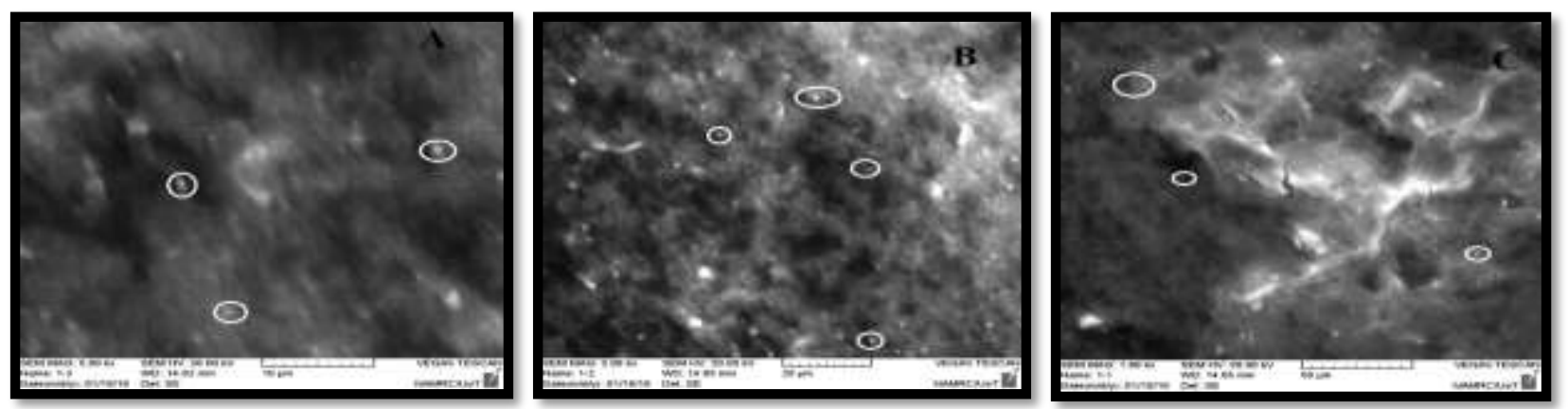

Figure (11). SEM images of synthesized AuNPs $(A=10 \mu \mathrm{m}, \mathrm{B}=20 \mu \mathrm{m}, \mathrm{C}=50 \mu \mathrm{m})$. 


\section{(f) Qualitative and Quantitative assay of Free Radical Scavenging Activity}

The main mechanism of antioxidant action in foods is radical scavenging activity. Therefore, many methods had been developed in which the antioxidant activity was evaluated by the scavenging of synthetic radicals in polar organic solvents such as methanol [27]. In free radical scavenging activity, DPPH is one of the stable and commercially available organic nitrogen radical which has a UV-VIS maximum absorption at $517 \mathrm{~nm}$ [28]. Radical-scavenging properties of gallic acid, AuNPs are evaluated against the DPPH radical. By using DPPH as a TLC spray (gallic acid, AuNPs) appeared as yellow spots against a purple background as illustrated in Figure (12).

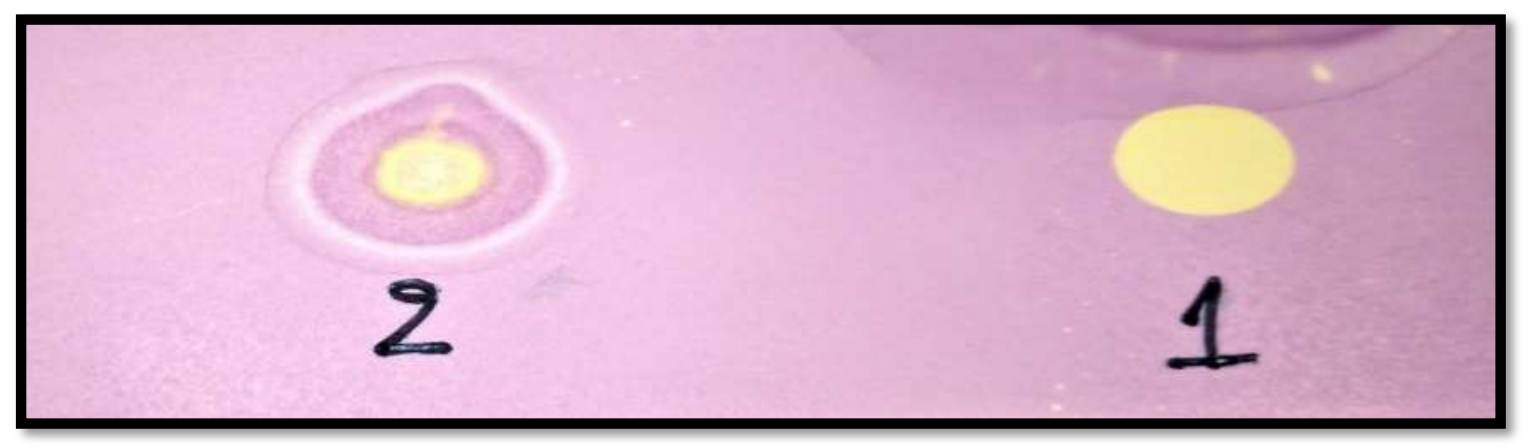

Figure (12). The TLC photo-image of (1) gallic acid, (2) AuNPs appear as yellow spots against a purple background.

Furthermore, the antioxidant activities of AuNPs were determined using free radical scavenging activity (quantitatively). The color altered from purple into yellow as the molar absorptivity of the DPPH radical at $517 \mathrm{~nm}$ reduce via transfer of acidic $\mathrm{H}$-atom from the compound to DPPH radical in order to produce DPPH-H. The results are summarized in Table (1) and Figure (13). The results indicate that it has been a potent scavenging activity with $\mathrm{IC}_{50}$ for standard gallic acid is $(21 \mu \mathrm{g} \backslash \mathrm{mL})$, and $(13 \mu \mathrm{g} / \mathrm{mL})$ for AuNPs as showed in Figures (13).

Table (1). The percentage inhibition of AuNPs using DPPH model.

\begin{tabular}{|c|c|c|}
\hline concentrations $(\boldsymbol{\mu g} / \mathbf{m L})$ & $\begin{array}{r}\text { \% Inhibition of } \\
\text { standard gallic acid solution }\end{array}$ & $\begin{array}{c}\text { \% Inhibition } \\
\text { (AuNPs) }\end{array}$ \\
\hline 10 & 43.98 & 47.2 \\
\hline 15 & 46.01 & 53.8 \\
\hline 25 & 83.4 & 55.9 \\
\hline 50 & 60.6 & 66.1 \\
\hline 60 & $\mathbf{8 2 . 9}$ & $\mathbf{7 1 . 3}$ \\
\hline
\end{tabular}
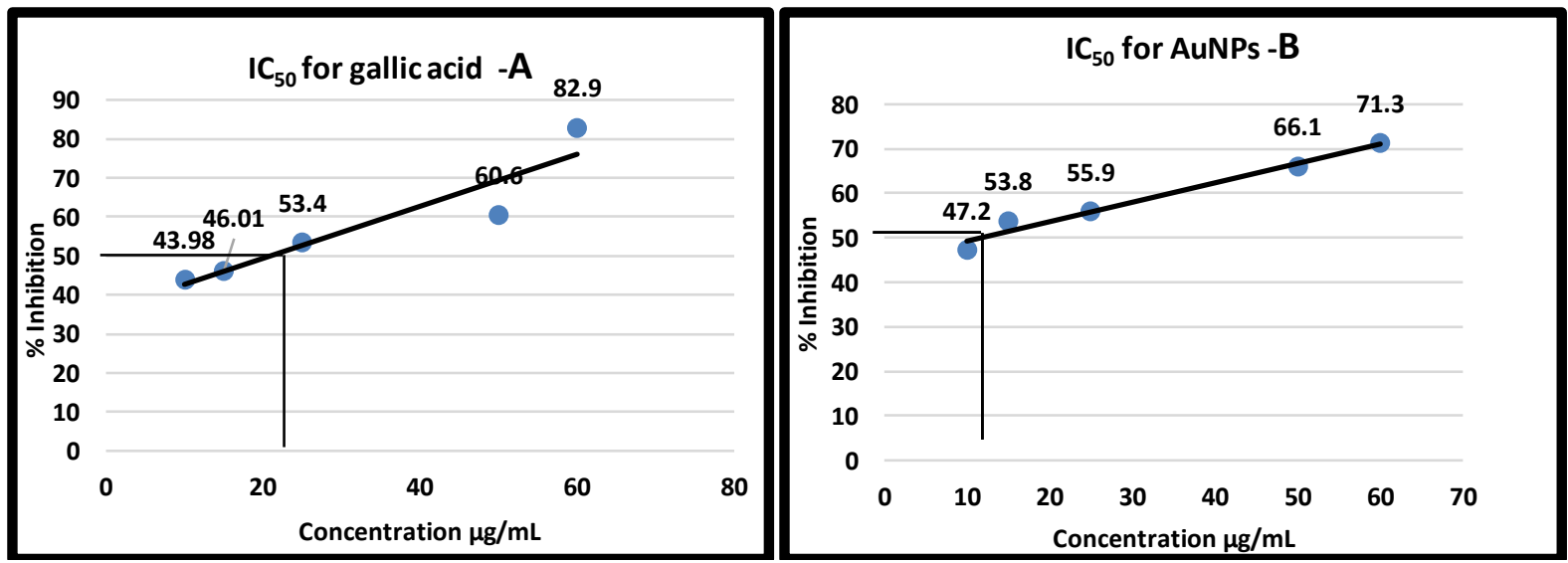

Figure (13). DPPH free radical scavenging activity of standard gallic acid (A) and AuNPs (B). 
This peel extract and biosynthesized AuNPs prepared from this extract have a potent scavenging activity which could be used as anti-bacterial and anti-inflammatory. The $\mathrm{HAuCl}_{4}$ require a suitable functional group in $G$. mangostana peel extract to react with gold ions and produce AuNPs, the various components of extract could be attached to the surface of gold, then formed the surface of the AuNPs functional, as illustrated in Figure (14).

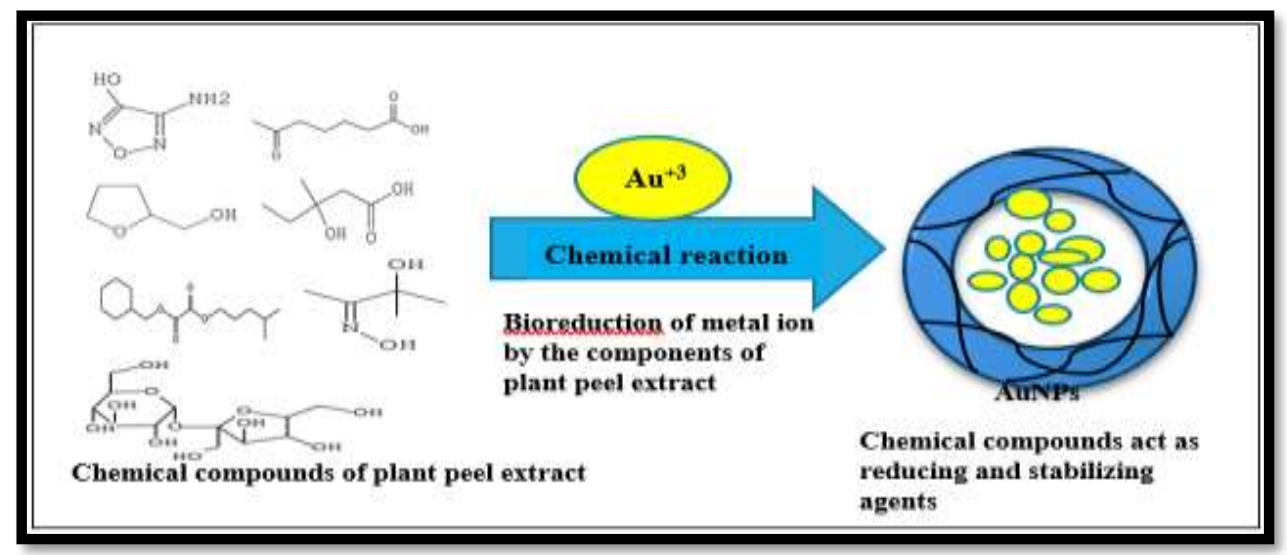

Figure (14). Chemical compounds of G. mangostana peel extract might be responsible for the bioreduction of gold metal ions.

\section{(g) Antibacterial Activity}

In the present study, two pathogenic bacteria (E. coli and S. aureus) were used in this test as shown in Figure (15). The diameters of the inhibitory region are presented with each extract to the selected bacteria. All extracts; ethanolic extract of G.mangostana peel, aqueous extract of G.mangostana peel and AuNPs which exhibited inhibitory regions of about 6-12 $\mathrm{mm}$ against studied bacteria, suggesting a broad activity to both positive and negative gram-negative bacteria, these results are in agreement with the study of Rajakannu and co-workers [28].

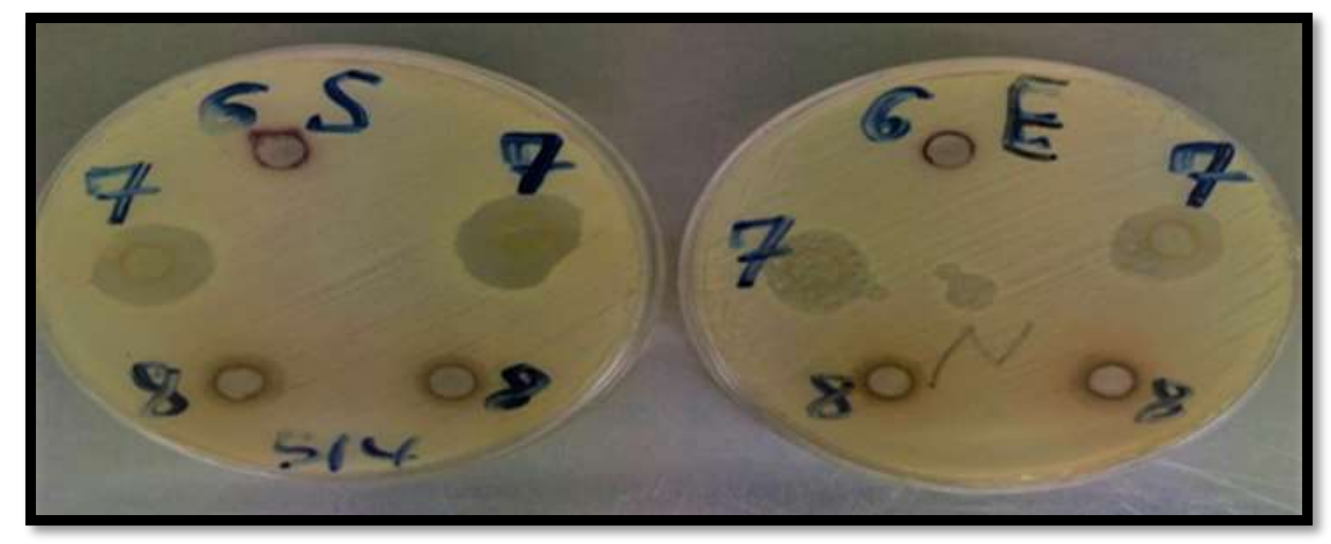

Figure (15). The inhibition zone for $(6=\mathrm{AuNPs}, 7=$ Ethanolic extract of $G$. mangostana, $8=$ Aqueous extract of G.mangostana, $\mathrm{S}=S$. aureus, $\mathrm{E}=$ E. coli).

It is obvious that smaller particles can elevate the ability for penetrate the membrane of cell and give more bactericidal effect. A many of atoms available produce their action faster and hence produce them more suitable for variety of applications. This characteristic enhances the biological and chemical activity of the NPs with high antibacterial efficiency [29]. All this results opens the way for demonstrating the effectiveness of AuNPs in wounds healing and acting as an anti-inflammatory agent.

\section{(h) The LDs0 Examination and Histological Study}

The toxicity test of AuNPs is shown in Table (2). The laboratory animal showed a number of clinical signs at the time of direct administration and continued signs for a period of time may range from one to several hours, but generally ended and returned to normal state after 24 hours of giving and may return to the normal state. 
Furthermore, AuNPs have no morbidity of all dose used with only some clinical signs, which means that AuNPs is not toxic in doses used.

Table (2). The $\mathrm{LD}_{50}$ examination and sign of animal treated with AuNPs.

\begin{tabular}{|c|c|c|c|c|}
\hline Number & $\begin{array}{l}\text { Dose of } \\
\text { AuNPs }\end{array}$ & $\begin{array}{l}\text { No. of mice } \\
\text { per group }\end{array}$ & $\begin{array}{l}\text { No. of dead/ No. } \\
\text { of animal }\end{array}$ & Sign of animal treated with extract \\
\hline 1 & $\begin{array}{c}13.6 \\
\mathrm{ppm} / \mathrm{mL}\end{array}$ & 2 & $0 / 2$ & $\begin{array}{l}\text { Slight as well as superfacial of scoliorachitic to a } \\
\text { few minute }\end{array}$ \\
\hline 2 & $8 \mathrm{ppm} / \mathrm{mL}$ & 2 & $0 / 2$ & Tacky cardiac, accelerate breathing. \\
\hline 3 & $2 \mathrm{ppm} / \mathrm{ml}$ & 2 & $0 / 2$ & $\begin{array}{l}\text { Tacky cardiac, increase breathing, slight and } \\
\text { superfacial of scoliorachitic to a few minutes; } \\
\text { which converted finally to ballooning like }\end{array}$ \\
\hline 4 & 0 & 2 & $0 / 2$ & Control \\
\hline
\end{tabular}

\section{(i) Histopathological Study}

The histopathological examination of collected groups in the present study show: In liver section for the treated group by $2 \mathrm{ppm} / \mathrm{mL}$ of AuNPs. Figure (16a \& b) shows sinusoidal dilation with an accumulation of glycoprotein granules with slight congestion, while liver section of the group treated with $13.6 \mathrm{ppm} / \mathrm{mL}$ of AuNPs (Figure 16, C\&D) shows congestion, widening of a sinusoid with an accumulation of cholesterol.

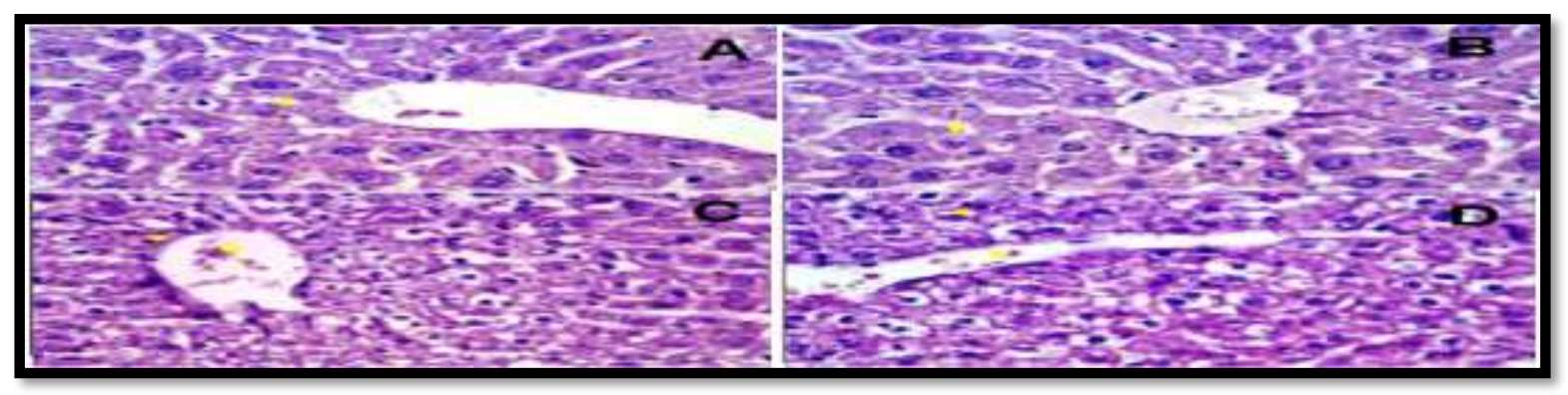

Figure (16). (a \& b) Liver section of group treated with $2 \mathrm{ppm} / \mathrm{mL}$ of AuNPs (X400): Sinusoidal dilation with accumulation of glycoprotein granules with slight congestion. (C\&D) The group treated with $13.6 \mathrm{ppm} / \mathrm{mL}$ of AuNPs (X400): Congestion, widening of sinusoid with accumulation of cholesterol material.

In Brain section of treated group by $2 \mathrm{ppm} / \mathrm{mL}$ of AuNPs. Figure (17a \& b) shows few necrotic glial cells, while other is still living. Brain section of treated group by $13.6 \mathrm{ppm} / \mathrm{mL}$ of AuNPs. Figure (17c) shows mild degenerative glial cell.

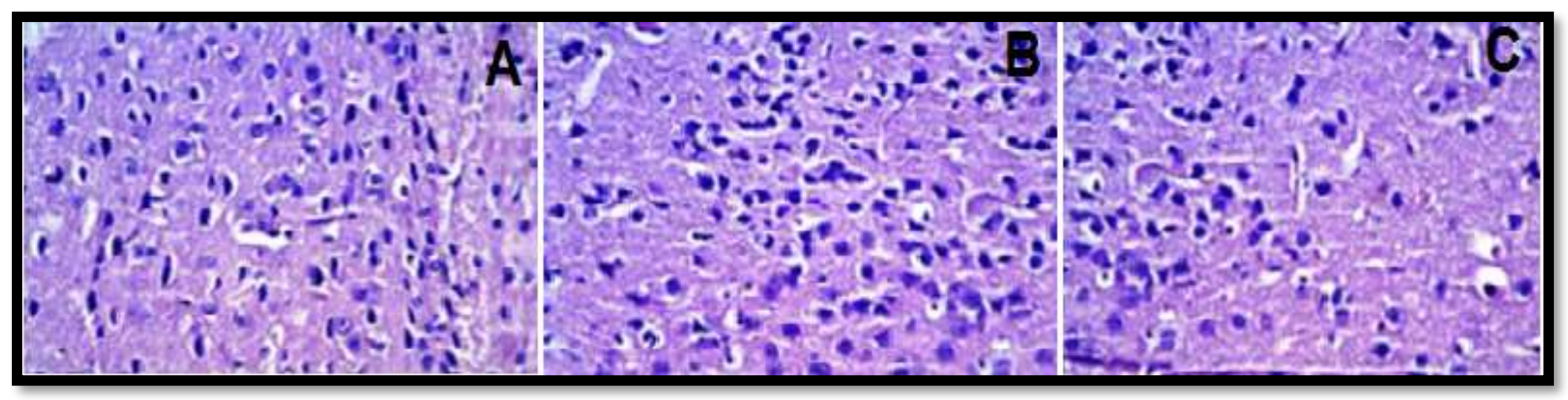

Figure (17). (A\&B) Brain section of treated group by $2 \mathrm{ppm} / \mathrm{mL}$ of AuNPs (X400): few necrotic glial cells and other are still living. (C)The group treated with $13.6 \mathrm{ppm} / \mathrm{mL}$ of AuNPs (X100): mild degenerative glial cell. 
In control group of mice, the liver and brain section shown in Figure (18a \& b), respectively.

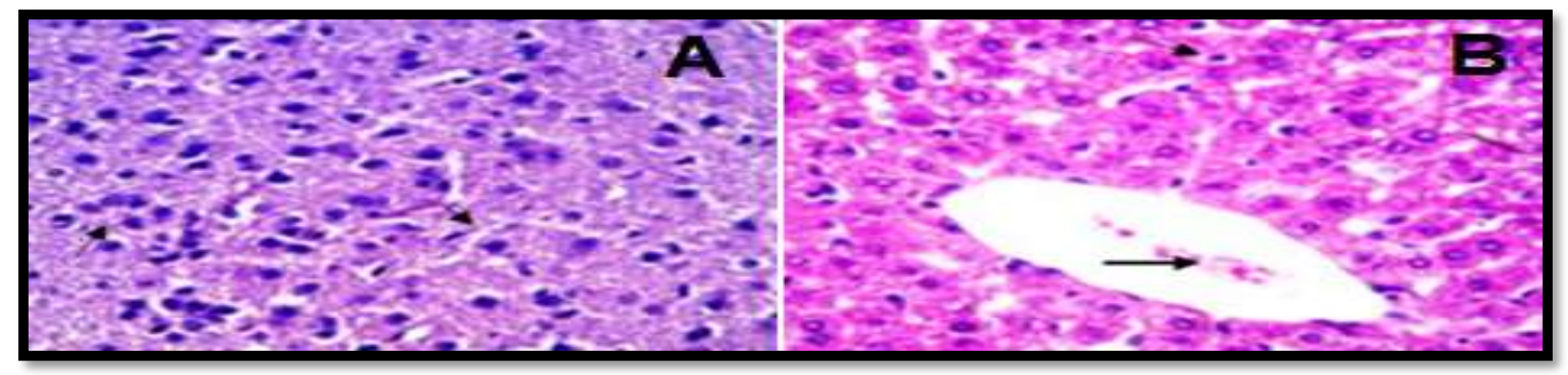

Figure (18). (A) Control liver section of mice (H\&Ex400): The section reveal radial arrangement of hepatocyte, sinusoid originates at lobules margin toward the hepatic vein (C.V.). (B) Control brain section of mice (H\&Ex400): normal histological appearance of glial cell,

In the case of other groups treated with AuNPs, the mice indicate a clinical signs inversely proportional to concentration of the extract used. In the low concentration of $2 \mathrm{ppm} / \mathrm{mL}$, there were severity of the clinical signs observed while in $13.6 \mathrm{ppm} / \mathrm{ml}$, the clinical signs were decreased. There is a correlation between herbal extract and NP principally depend on the concentration thus leads to the appearance of many clinical signs. On the other hand, both extract and AuNPs didn't show any sign of mortality or morbidity in all treated groups [30, 31]. The experimental groups exhibited variable degrees of hepatic affection and this could be attributed to the oxidative stress induced by extraction [32]. The AuNPs tried to ameliorated the hepatocellular damage induced by extract in vital organ which induced hepatotoxicity in mice. The liver or brain section are emerge in slight defect may be due to elevated hepatoprotective activity of NP began to take their way by bioavailability and absorption of AuNPs in vivo increases and appear as reducing the damage in hepatocyte cell [33]. Also the presence of congestion in blood vessels may be due to attachment of NPs to RBCs simultaneously elevate of their levels in blood and these idea produce a new platform for improving the blood pharmacokinetics and vascular delivery of NPs, while simultaneously avoiding uptake by liver, thus opening the ways to study many applications [34].The AuNPs was administered in mice, NPs was detected in different organs including the brain, indicating that they can cross the blood brain barrier, which shown significantly in the site. Group treated with AuNPs showed mild degeneration of cells which could be a result of the antioxidant effect of the extract which mainly appears in high doses only[35].

\section{(j) Treatment of Developed Wounds (Wounds Healing)}

The using of cream contains AuNPs to treated the wounds of mice were compared with standard (fucidin). The ability of this cream made the wound healing developed fast as seen in Figure 19, the cream speeds up the process of the formation of scar tissue in the outer skin areas[36]. One of the explanations is the effectiveness of AuNPs that interact with the components of cream, giving cream more impact therapeutic role. The cream works on the formation of the outer cover surrounds the open wound completely, so that it can be avoided it from external influences, as well as the ability of the cream to penetrates into the skin tissue which increases the tensile strength in the skin tissue and increases the production of the epithelial layer and collagen formation around the wound area, thus enhance the healing process and return the mouse skin to its normal state with time progress, as indicated in Figure (20). Furthermore, no side effects or changes in mice behavioral were observed with along treatment period. 


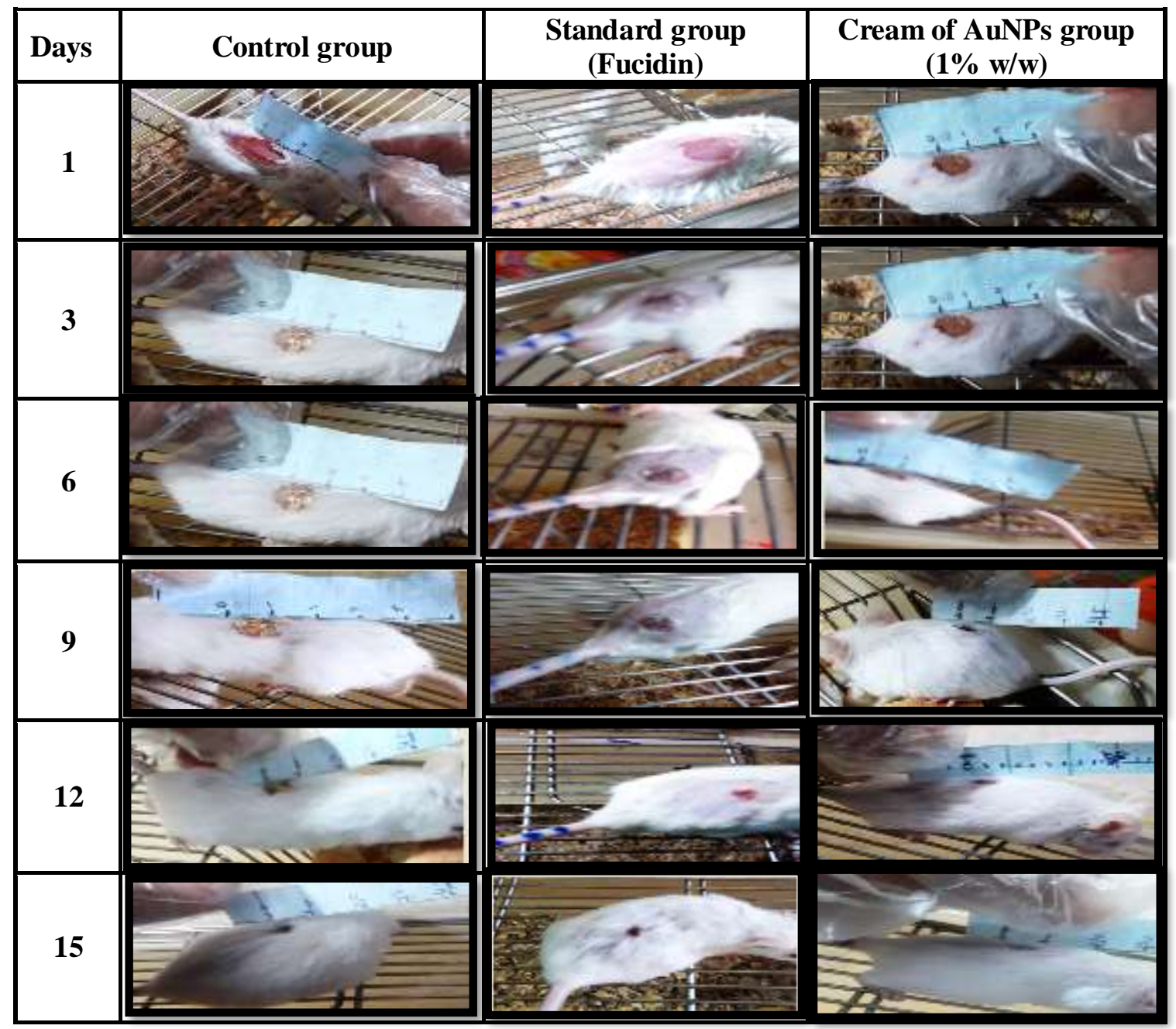

Figure (19). The effectiveness of the pharmaceutical formulation of AuNPs cream at a concentration of $1 \%$ w/w in wounds healing created on the skin of mice.

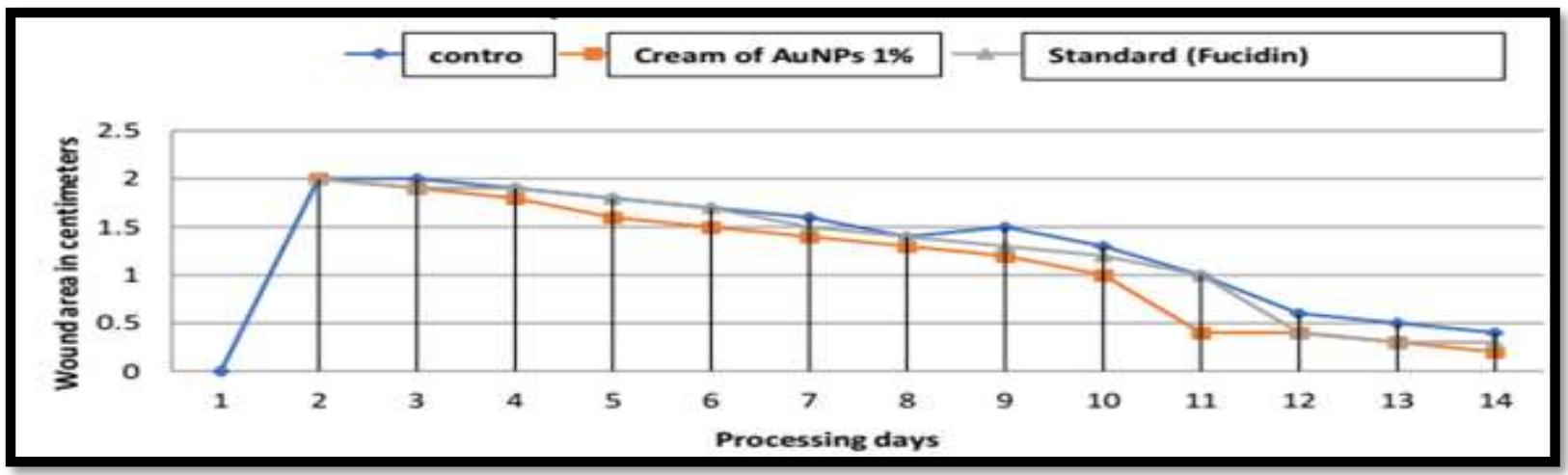

Figure (20). Effect of $1 \%$ AuNPs cream treatment of open wound for white mice according to processing days. The area of the wound was measured by the measuring tape

\section{(k) Histopathological Changes}

Histopathological changes in mice skin tissues that treated by AuNPs cream, at 15 days after-injury, have shown a complete re-epithelialization and epithelium is thicker than a control section. From the other side, the treated tissue indicates low inflammatory cells in comparison to other groups as shown in Figure (21). 


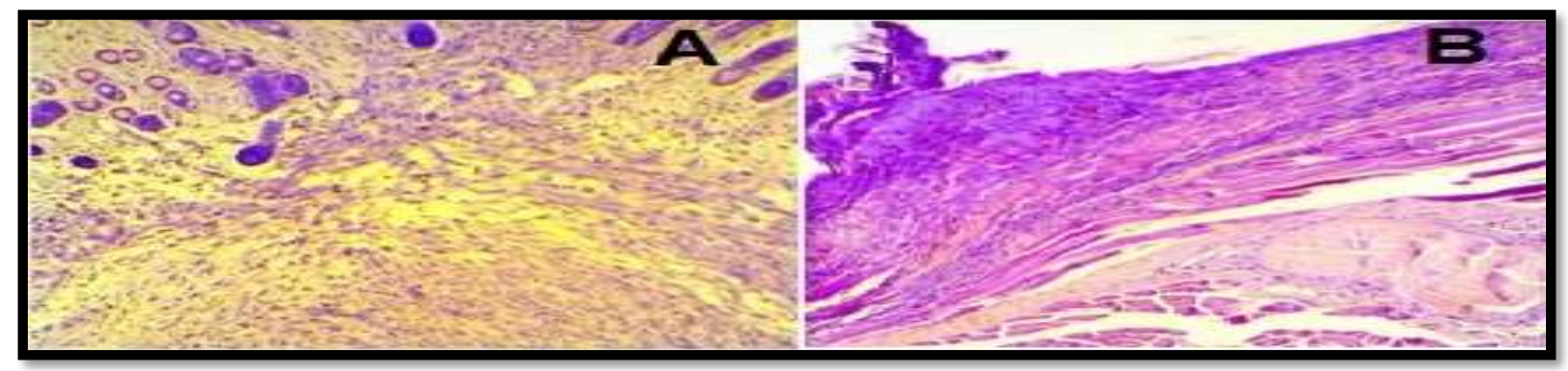

Figure (20). (A) Skin tissue section of control group (x100) (H\&E) (B) Skin tissue section of treated group by AuNPs cream 1\% (x100) (H\&E).

The existing of neutrophils in the treated lesions with many fibroblasts as well as loops of new growing blood vessels have been show in the repaired one, which existing at the site of injury. Actually, in this group, the rate of healing was more quickly than other groups. Furthermore, comparing of the treated mice used AuNPs cream with other groups indicate that injured area are dropped in thickness, may be due to elevate in the inflammatory cells at the site with better maturation of the repair cells, enhanced the fibroblasts, collagen fibers as well as blood vessels content. Mice treated by biosynthesized AuNPs cream illustrated greater area of wound healing than other groups, may be due to decrease neutrophils, which means that AuNPs has anti-inflammatory effects can accelerate healing. The accelerated healing in skin section may be due to effectiveness of biosynthesized AuNPs cream, which play a potential role in wound repair process and they illustrated that this process will accelerate by fibroblast production [37].

\section{Conclusions}

Extract of G. mangostana work a significant role in the reduction and stabilization of gold and converting to AuNPs. The results implied that the synthesis of the AuNPs elevated significantly in acidic media with elevating temperature. Analysis using UV-Vis, FT-IR, AAS, AFM, SEM and Zitasizer, are good tools to specify and characterized the formation of AuNPs. The AFM and SEM assay confirm that the size of particles is between 15$100 \mathrm{~nm}$, with spherical structure. The significant biosynthesized AuNPs illustrate an effectively potent agent against both gram-negative, gram-positive bacteria. The biogenic synthesis of AuNPs indicated more potent antioxidant activity as comparison to G. mangostana peel extract alone. Histological study indicated that both of peel extract and biosynthesized AuNPs have no toxic effect, with great ability to wound healing when converted to cream. Many factors could be contributed in the enhancement of the wound healing process. The exciting of antioxidant, anti-inflammatory and antimicrobials properties of their phytochemical components may be among the factors that contributed to the potential wound-healing effect. So, these properties may be helpful in different applications in pharmaceutical, biomedical fields.

Acknowledgement: The authors would like to thank Mustansiriyah University (www.uomustansiriyah.edu.iq), Baghdad-Iraq, for its support in the present work.

\section{References}

[1] N. A. Singh, "Nanotechnology innovations, industrial applications and patents," Environ Chem Lett, vol. 45, pp.185-191, 2017.

[2] S. Arokiyaraj, S.Vincent, M. Saravanan, Y. Lee, Y. K. Oh, et al., "Green synthesis of silver nanoparticles using Rheum palmatum root extract and their antibacterial activity against Staphylococcus aureus and Pseudomonas aeruginosa," Artificial cells, nanomedicine, and biotechnology, vol. 45, no. 2, pp. 372-379, 2017.

[3] M. A. K. Abdelhalim, and Moussa S. A. A., "The gold nanoparticle size and exposure duration effect on the liver and kidney function of rats: In viv," Saudi journal of biological sciences, vol. 20, no. 2, pp. 177-181, 2013.

[4] H. A. Khan, M. A. K. Abdelhalim, M. S. Al-Ayed, and A. S. Alhomida, "Effect of gold nanoparticles on glutathione and malondialdehyde levels in liver, lung and heart of rats," Saudi journal of biological sciences, vol. 19, no. 4, pp. 461-464, 2012. 
[5] K. X. Lee, K. Shameli, M. Miyake, N. Kuwano, N. B. A. Khairudin, S. E. Bt Mohamad., et al.," Green synthesis of gold nanoparticles using aqueous extract of Garcinia mangostana fruit peels,"Journal of Nanomaterials,vol. 2016, 2016.

[6] M.Y. Ibrahim, N. M. Hashim, A. A. Mariod, S. Mohan, M. A. Abdulla, S. I. Abdelwahab,et al.," a-Mangostin from Garcinia mangostana Linn: an updated review of its pharmacological properties," Arabian journal of Chemistry, vol. 9, no. 3, pp. 317-329, 2016.

[7] A. Tachaprutinun, M. C. Meinke, H. Richter, P. Pan-In, S. Wanichwecharungruang, F. Knorr, J. Lademann

, et al.," Comparison of the skin penetration of Garcinia mangostana extract in particulate and non-particulate form," European Journal of Pharmaceutics and Biopharmaceutics, vol. 86, no. 2, pp. 307-313, 2014.

[8] C. Li, X. Miao, F. Li, S. Wang, Q. Liu, Y. Wang, et al.," Oxidative stress-related mechanisms and antioxidant therapy in diabetic retinopathy" Oxidative Medicine and Cellular Longevity, vol. 2017. 2017.

[9] Manisha, W. Hasan, R. Rajak, and D. Jat," Oxidative Stress and Antioxidant: An Overview," International Journal of Advanced Research and Review, vol. 2, no. 9, pp. 110-119, 2017.

[10] G. S. Lazarus, D. M.Cooper, D. R. Knighton, D. J. Margolis DJ, R. E. Pecoraro, G. Rodeheaver, et al., "Definitions and guidelines for assessment of wounds and evaluation of healing," Wound Repair and Regeneration, vol. 2, no. 3, pp. 165-170, 1994.

[11] M. A. Palladino, F. R. Bahjat, E. A. Theodorakis, and L. L. Moldawer, et al.," Anti-TNF- $\alpha$ therapies: the next generation, " Nature reviews Drug discovery, vol. 2, no. 9, pp. 736-746, 2003.

[12] S. H. Freiesleben, J. Soelberg, N. T. Nyberg, and A. K. Jäger,"Determination of the wound healing potentials of medicinal plants historically used in Ghana," Evidence-Based Complementary and Alternative Medicine, vol. 2017, 2017.

[13]V. P. Zharov, K. E. Mercer, E. N. Galitovskaya, and M. S. Smeltzer," Photothermal nanotherapeutics and nanodiagnostics for selective killing of bacteria targeted with gold nanoparticles, "Biophysical journal, vol. 90, no. 2, pp. 619-627, 2006.

[14] A.M.N. Jassim, , S.A. Farhan and R.M. Dadoosh, "Green synthesis of silver nanoparticles using seed aqueous extract of Abelmoschus esculentus and study of their properties, " Advances in Environmental Biology, vol. 10, no.4, pp. 51-67, 2016.

[15] M.A. Mahdi, M. T. Mohammed, A. M. N. Jassim, and A. I. Mohammed, " Phytochemical content and antioxidant activity of Hylocereus undatus and study of toxicity and the ability of wound treatment," Plant Archives, vol. 18, no.2, pp. 2672-2680, 2018.

[16] S. Soufane, A. Bouzidi, N. Mahdeb, and S. Krache, "Evaluation of Acute and Subacute Toxicity of Fruit Methanolic Extract from Citrullus colocynthis in male Albino rats, " International Journal of Pharmacognosy and Phytochemical Research, vol. 9, no. 4, pp. 557-86, 2017.

[17] M. Slaoui, A.L. Bauchet, and L. Fiette," Tissue Sampling and Processing for Histopathology Evaluation," Methods Mol Biol., vol. 1641 pp. 101-114, 2017.

[18] B. C. Prakashbabu, D. Vijay, S. George, S. Kodiyil, S. N. Nair, A. K. Gopalan, et al., "Wound Healing and Anti-Inflammatory Activity of Methanolic Extract of Gmelina arborea and Hemigraphis colorata in Rats," Int. J. Curr. Microbiol. App. Sci, vol. 6, no. 8, pp. 3116-3122, 2017.

[19] S. Iravani, "Green synthesis of metal nanoparticles using plants," Green Chemistry, vol. 13, no. 10, pp. 2638$2650,2011$.

[20]C. Coman, L. F. Leopold, O. D. Rugină, L. Barbu-Tudoran, N. Leopold, and M. Tofană , et al., "Green synthesis of gold nanoparticles by Allium sativum extract and their assessment as SERS substrate," Journal of nanoparticle research, vol. 16, no. 1, p. 2158, 2014 .

[21]M. Faried, K. Shameli, M. Miyake, H. Hara, and N. B. A. Khairudin, "Synthesis of silver nanoparticles via green method using ultrasound irradiation in seaweed Kappaphycus alvarezii media," Research on Chemical Intermediates, vol. 10, no. 4, pp. 1416-1426, 2015.

[22] K. J. Rao, and S. Paria, "Aegle marmelos leaf extract and plant surfactants mediated green synthesis of $\mathrm{Au}$ and Ag nanoparticles by optimizing process parameters using Taguchi method, "ACS Sustainable Chemistry \& Engineering, vol. 3, no. 3, pp. 483-491, 2015.

[23] K. Shameli, M. Bin Ahmad, P. Shabanzadeh, E. A. J. Al-Mulla, A. Zamanian, Y. Abdollahi, et al., "Effect of Curcuma longa tuber powder extract on size of silver nanoparticles prepared by green method," Research on Chemical Intermediates, vol. 40, no. 3, pp. 1313-1325, 2014.. 
[24] N. K. R. Bogireddy, K.K.H. Anand, and B.K. Mandal," Gold nanoparticles—synthesis by Sterculia acuminata extract and its catalytic efficiency in alleviating different organic dyes," Journal of Molecular Liquids, vol. 211, pp. 868-875, 2015.

[25] L. J. Harrison, "Xanthones from the heartwood of Garcinia mangostan,". Phytochemistry, vol. 60, no. 5, pp. 541-548, 2002.

[26] G.M. Shafy, A. M. N. Jassim, and M.T. Mohammed," Study of phytochemical, antioxidant and antiinflammatory of Mangosteen (G.mangostona) and its ability to wound healing," Plant Archives, vol. 19, no. 1, pp. 665-673, 2019.

[27] D. Huang, B. Ou, and R.L. Prior, "The chemistry behind antioxidant capacity assays,"Journal of agricultural and food chemistry, vol. 53, no. , pp. 1841-1856, 2005.

[28] S. Rajakannu, S. Shankar, S. Perumal, S. Subramanian, and G. P. Dhakshinamoorthy, "Biosynthesis of silver nanoparticles using Garcinia mangostana fruit extract and their antibacterial, antioxidant activity," Int. J. Curr. Microbiol. Appl. Sci., vol. 4, pp. 944-952, 2015.

[29] M. Bindhu and M. Umadevi," Antibacterial activities of green synthesized gold nanoparticles," Materials Letters, vol. 120, pp. 122-125, 2014.

[30]J. D. Lambert, M. J. Kennett, S. Sang, K. R. Reuhl, J. Ju, and Chung S Yang," Hepatotoxicity of high oral dose (-)-epigallocatechin-3-gallate in mice, " Food and chemical toxicology, vol. 48, no.1, pp. 409-416, 2010.

[31]I. G. Saleh, Z. Ali, N. Abe, F. D Wilson, F. M Hamada, M. F. Abd-Ellah, et al., " Effect of green tea and its polyphenols on mouse liver," Fitoterapia, vol. 90, pp. 151-159, 2013.

[32] V. V. Serov, "Nature of cloudy swelling and granular degeneration of parenchymatous organs," Arkh Patol, vol. 53, no. 2, pp. 3-6, 1991.

[33] P. D. Yurchenco and B. L. Patton," Developmental and pathogenic mechanisms of basement membrane assembly, " Current Pharmaceutical Design, vol. 15, no.12, pp. 1277-1294, 2009.

[34] B. Clément, P. Y. Rescan, G. Baffet, O. Loréal, D. Lehry, J. P. Campion, et al. ," Hepatocytes may produce laminin in fibrotic liver and in primary culture," Hepatology, vol. 8, no. 4, pp. 794-803, 1988.

[35] Y. M. Tsai,C. F. Chien, L. C. Lin, and T. H. Tsai," Curcumin and its nano-formulation: the kinetics of tissue distribution and blood-brain barrier penetration, " International journal of pharmaceutics, vol. 416, no. 1, pp. 331-338, 2011.

[36] G. R. M. Perez, S. R. Vargas, and H. Y. Ortiz, " Wound healing properties of Hylocereus undatus on diabetic rats," Phytotherapy Research, vol. 19, no.8. pp. 665-668, 2005.

[37] N. Shafeie, A.T. Naini, and H.K. Jahromi," Comparison of different concentrations of Calendula officinalis gel on cutaneous wound healing, "Biomedical and Pharmacology Journal, vol. 8, no. 2, pp. 979-992, 2015. 